\title{
POSITIVE ATTITUDE BUILDOUT AT SECOND GRADERS THROUGH OUTDOOR EDUCATION ACTIVITIES
}

\author{
Henrietta TORKOS, Ph.D Candidate, \\ Aurel Vlaicu University of Arad \\ torkos henriette@yahoo.com
}

\author{
Alina Felicia ROMAN, PhD Unievrsity Proffesor, \\ Aurel Vlaicu University of Arad \\ romanalinafelicia@yahoo.com
}

\begin{abstract}
Outdoor education has come to the point where, besides being a modern teachinglearning method, it can easily develop certain competencies if it is done according to strategical rules. Modern education is based on the development of competencies and the curriculum motivates the use of activities that can build these in children of any age. One of the most important parts of a competency is the attitude of pupils towards oneself, others and learning. This study, presents the theoretical base of attitudes as parts of competencies and how pupils can achieve them through formal education. It also presents a research amongst a group of second graders from Arad County based on outdoor learning activities and the multiple ways in which these can develop attitudes in the research group. We are going to present the instruments and the results, which preliminarily show that involving kids in outdoor learning activities can successfully develop positive attitudes towards self, society, the micro group and towards learning.
\end{abstract}

Key words:attitudes; buildup; outdoor education; competencies; group;

\section{Introduction}

There are many ways through which education can be done and competencies can be developed. Teachers all over the world can choose from many methods and educational procedures in order to get to the results that they desire and to get as closer as possible to the educational ideal that can be found in the National Curriculum.

There are also competencies that can be found in the National Curriculum of every educational system, that have to be developed throughout every scholar year, regardless the fact that they are key competencies or transversal ones. In the latest years, there has been a great emphasis on the development of transversal competencies and mostly on the buildup of the three components of every competency: knowledge, ability and attitudes.

Unfortunately there is a less emphasis on the last one, and a bigger emphasis on the first one. Usually, because educational systems are built in order to develop and evaluate knowledge and sometimes abilities. The attitudinal component of the competencies is often neglected in the instructive process. This fact can be explained by the difficulty of evaluating it and also because of the fact that teachers and parents, also community ask for results that translate through grades and marks, not behavior of pupils.

In the following, we are going to present one modern educational strategy through which attitude of pupils can be successfully developed in order for them to become independent and successful learners and then useful members of the community. Also by having a positive attitude towards learning, grades can increase and the atmosphere within the educational process can change in a positive way. Also, we are going to discuss the need of attitude buildup and we are going to present some results of introducing outdoor education in the instructive process and the way it changes attitudes towards self, others and learning. 


\section{Theoretical foundation}

In this paper, the concept of outdoor education will be used as a basic concept, both in the definition of the concept and in the explanation of the paradigms on which the concept is based, since we consider this term to be the most comprehensive as well as regarding the semantic analysis, both phonetic and etymological.

From etymological point of view, outdoor education refers to an organized learning situation that takes place in the external environment. Outdoor activities can often involve experiences based on near-trips through participation in a variety of adventures and outdoor activities such as hiking, climbing, canoeing, rope racing or group games. Therefore, outdoor education is based on the philosophy, theory and practice of experiential education.Also from the etymological point of view, another definition of outdoor education is noted, according to Smith, it is based on relationships and connections in terms of people and natural resources. The same Julian W. Smith described outdoor education as a learning environment for those contents that can best be assimilated outside the classroom. (Smith, 1955)

Outdoor education is a concept that takes into account an entire education program based on the experience and practical activity that takes place outside the classroom in the natural environment. It helps people to better understand themselves, to perceive more correctly the surrounding world and especially to gain a better knowledge of the people around them. It is considered a modern learning strategy with strong educational effects benefiting the development of innovative spirit, leadership, communication and other aspects of modern life.

The concept of outdoor education directs attention to an education based on experience and practical activities that take place outside the group halls, aiming at understanding the self, those around and the surrounding world. It is a relatively new type of education, producing long-lasting effects in terms of mastering complex learning situations and especially developing the skills necessary for modern life: innovation, leadership, team spirit, communication, autonomy and creativity. In our country, outdoor education belongs to nonformal education through extra-curricular activities outside the school environment, but is also used in formal education as a learning strategy or as a type of new education. (Șerban, 2014)

Definitions are categorized in the literature according to two major plans:

- From a psychological-socio-educational point of view

- From an environmental point of view.

From the point of view of the psychological-educational and social level, outdoor education is defined according to the Foreign Learning Institute as the use of external experiences in order to educate and develop the whole personality. Lewis, (Lewis, 1957) argues that outdoor education appeals to all the senses of the individual in order to observe and perceive the environment as efficiently as possible. Analyzed from a socio-educational point of view, and according to a more modern approach of the same author, outdoor education is defined as a phenomenon of Western postmodern society. It does not take place as we currently understand and define in Eastern society or pre-modern Western society. It is necessary to distance civilization from nature, for nature to have new effects and to stimulate education so that outdoor learning can be regarded as worthy of identification. (Neill, 2004)

From the environmental point of view, outdoor education is defined as an experimental learning process involving all the senses of the participants, which takes place primarily, but not exclusively, through exposure to the natural environment. (Priest, 1990) This definition is complemented by the following: Exiting in the natural environment, learning and respecting the environment. (Ketchie, nd)

The objectives of outdoor learning can include: knowledge and understanding of geographic processes or plant growth techniques, attitudes towards the future or towards society, values and feelings related to the environment or self, assimilation of skills such as orientation in space or communication, behaviors such as personal and group interactions, 
coping strategies, personal development and the development of self-confidence. Outdoor learning places can include: school grounds or gardens, wilderness areas, urban spaces, rural farms, parks and gardens, natural centers, etc. (Bilton, 2010)

\section{Directions}

Throughout the history of pedagogy, fluctuations can be noticed as regards the roles used in the educational process, the objectives set, the contents addressed, but especially the intended objectives. Each time, these features have been dealt with based on the individual needs of the educator, but also on social needs and expectations. Until recently, the emphasis was on the accumulation of theoretical knowledge and information, the pedagogy of the present starts from a preview of the future in what challenges and needs can arise. With socialization developing socially, education has had to move to a different level, namely to form individuals adaptable to new social requirements. The roles in the instructive-educational process were rethought. The teacher is no longer the sole source of information, nor is he solely responsible for the educational process. Parents and society have gained a significant role in shaping and developing children's personality by asking them for active involvement in learning. Students have become passive listeners, active participants, even proponents of learning situations and their assessors. So, a knowledge-based education has turned into a skillbased one. Knowing is no longer sufficient in a society that is constantly changing, but this science must be transposed into practice, adapted and adapted as often as necessary. It can therefore be said that pedagogy of the future is a pedagogy of competences.

It is not possible to achieve a complete definition of competencies without taking into account their component parts. The concept of competence as a variable of the educational process is preceded by other value acquisitions without which it cannot exist. According to Miron Ionescu (Ionescu, 2003), knowledge is given and information that is subject to analysis, observation and synthesis and passing through the student's thinking filter. Skills are the ability to effectively perform intellectual and practical operations. Skills are components of abilities and activity, originally developed consciously, but which then become automatisms. Also they are systems of sensory-motor, cognitive, affective-motivational and volitional components, ensuring the success of an activity. Capacities are psychological-individual attributes that allow for good performance in a certain area, using minimal energy.

Competencies represent a set of capabilities and skills used in the application, operation and transfer of acquisitions that enable the efficiency of an activity to be carried out, but also the functional use of knowledge, skills and skills acquired both in formal, non-formal and informal contexts. (Roman, Balaș, 2010)

Skills-based education is education that looks to the future and prepares to cope with it. Action, activity and interactivity, as well as the involvement and accountability of educators are the first steps in skills training. Transdisciplinary learning and multiple dimensions of contemporary life require acquiring skills that propel the individual into the much-desired places in society. The experiences and experiences of the individual complement the learning and reorganize it so that modern education really responds through innovative educational practices to the requirements of modern society.

Transversal competences are value acquisitions and attitudes that go beyond a specific field or study program and are expressed through the following descriptors: autonomy and responsibility, social interaction, personal and professional development. (Ilica, 2013)

Cross-skills are based on the following skills, abilities and attitudes:

- Interpersonal skills: organizational, communication, collaboration and teamwork, socialization, collegiality, empathy and compassion. 
- Intrapersonal skills: discipline, the ability to learn individually and independently, flexibility and adaptability, self-awareness, perseverance and self-motivation, compassion, integrity and self-esteem.

- Critical and innovative thinking: creativity, entrepreneurship, reflective thinking and reasoning in decision-making.

- Global citizenship spirit: openness and civic conscience, tolerance and respect for diversity, responsibility and conflict resolution, ethical and intercultural understanding, democratic participation, respect for the environment, national identity and sense of belonging, ability to critically evaluate information, and media content and the ability to obtain and analyze information through computerized and technological tools.

- Other: appreciation of a healthy lifestyle and respect for religious values.

\section{Recent perspectives}

The complexity of today's society demands that educational systems, through the educational and educational activities they organize, develop individuals prepared for social life but also developed complex, for a satisfactory personal life. This can only become possible if the educator goes through situations that can form him from the physical, social and psychological point of view. Education can do this by organizing activities where students can practice cohesion, cooperation, respect, self-esteem, self-discipline and care for the welfare of others. Outdoor education is a way in which these behaviors can be practiced in formal education. In this chapter we present the most important social and psychological aspects of outdoor education and the role played by each factor / partner involved in this type of education.

Outdoor education, through learning activities conducted in the external environment, is aimed at learning based on practical activities and learning experiences. It is a relatively new type of education that is considered in the literature as a learning strategy, correlating the philosophy, theory and practice of experiential learning, environmental education elements and environmental education. A conceptual differentiation of these three elements was made in the previous chapters. Outdoor education is approached in the educational field as a way of developing acquisitions such as self-esteem, self-understanding, a better understanding of the surrounding alum and the natural world. It also develops psychosocial characteristics from very young ages: leadership, innovation, communication and team spirit. In the following, we will address the topic of outdoor education from a holistic perspective, through the objective analysis of the benefits and plans of its manifestation. Then we propose to investigate the role of nature in the educational process and the attribution of adults in the planning and development of activities related to outdoor education.

Recent studies in the field of primary education have drawn the attention of specialists to the improvement of didactic methods and strategies, as well as to the activities carried out in the class of students. In the last period, it is desirable to renew pedagogical methods so that learning becomes one that targets new skills. Thus, teachers have to organize their educational approach taking into account: curricular provisions, organizational strategies and didactic methodology.

Second grade is the last level of the three inherent in the core procurement cycle. Specifically, by the end of the second grade, the desires of the child's training profile are achieved, and the pupil is expected to be able to:

- use various ways of communicating in real situations

- demonstrate creative thinking and adaptability to varying situations

- valuate their own experiences in investigating the natural and social environment

- to understand and perform social roles within different types of communities

- understand and use technologies appropriately 
- to internalize a set of individual and social values to guide their behavior

- to mobilize their own potential for building a quality life.

By thoroughly analyzing the skills required for a student who completed the second grade, completing the cycle of fundamental acquisitions, one can observe the requirement of a dynamic, natural, open education, an education that is in constant contact with the society and its members, but more chosen education that is constantly concerned with the environment, natural areas, harmonious physical and cognitive development in the natural environment. It is also seen to encourage self-discovery and relationships based on communication, sharing, discovery, experience, learning holistic and especially interdisciplinary. The aim of this level of education is to provide the conceptual, psychological and behavioral bases that allow the child to adapt effectively to the next level of schooling, but especially the social integration of each individual as quickly as possible. Skills can be gained more easily and faster if each teacher prepares the necessary space and resources for modern learning, starting from the needs and interests of each child. This can be done mainly through the use of outdoor education activities.

\section{Research}

The present study was conducted in the second class, from the urban environment, in an educational institution from the outskirts of Arad County. The institution has expressed a strong interest in participating to the study, both the experimental class and the control group.

The population was made up of pupils of second grade, urban-peripheral environment at a General School in Arad. The students participating in the present study were of both genders, ages 8 to 9 years. The distribution of the participating posology is homogeneous as a number and as an age group. Within the control group participated 15 students, compared to the experimental group, where 18 students participated. These classes are relatively small as the number of students, but considering the environment of the institution, we can say that the number of pupils is relatively balanced.

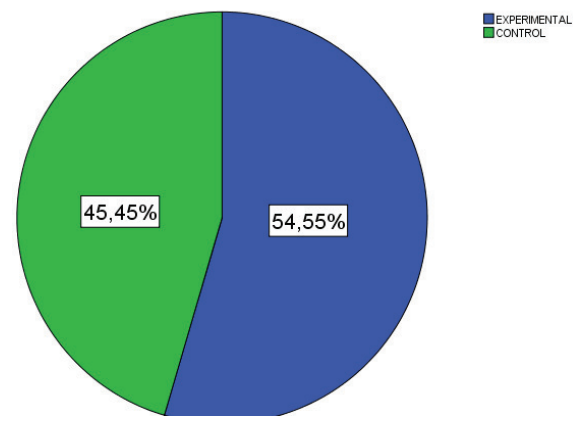

Graph nb. 1. The distribution of second graders in groups graph:

The distribution by gender was done within the two groups, as shown in the following

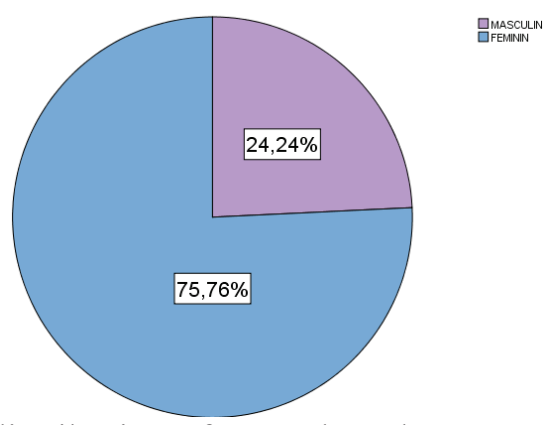

Graph nb. 2. The distribution of second graders according to the gender 


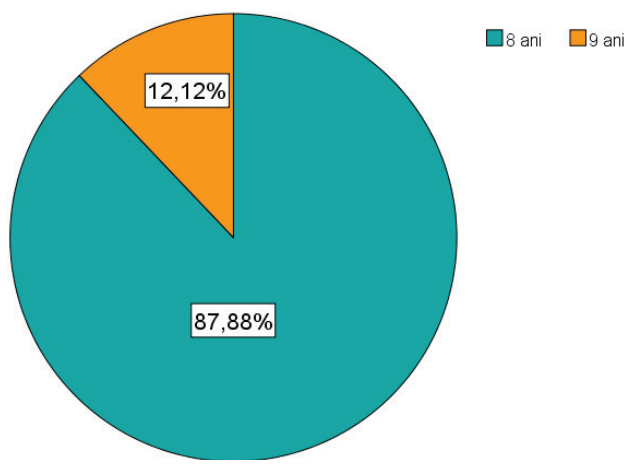

Graph nb. 3. The distribution of second graders according to their age

According to the graph above, it can be seen that the highest percentage is represented by the 8 -year-old pupils $(\mathrm{p}=87.88 \%$ ), followed by the 9 -year-old pupils $(\mathrm{p}=12.12 \%)$. In this study, there are no pupils from three separate age categories.

In order to present the results of the study, we have to mention that there have been used the method of outdoor education, with the following activities: a general culture activity, an orienteering activity and a mathematical activity. The instruments used to verify and evaluate the activities was the evaluation sheet of the competencies, based on three criteria: the cognitive criterion, the abilities criterion and the attitudinal criteria. In this study, we are only going to present the last criteria, the one that measures the development of attitudes at second graders during and after outdoor education activities, at both classes, the experimental group and the control group. During the evaluation, we have been using scores of two types: from 1 to 5 , and 1 and 5. This was important to specify because for each student in part there will be a final score of a maximum score set for each activity under the outdoor education.

\section{Hypothesis and results}

The main hypothesis of the present study was formulated as follows: There are significant differences in the results obtained between the experimental group and the control group in the second grade students, regarding attitudes towards learning.

In order to test this hypothesis, we used the t test, having as a variable the group of study and experimental and control subjects, and as a dependent variable, the results obtained in the post-test phase, structured on the three criteria at the level of each Class II observation sheet. We will present the results for the $1^{\text {st }}$ outdoor activity.

Group Statistics

\begin{tabular}{llrrrr}
\hline & GRUP & N & Mean & Std. Deviation & Std. Error Mean \\
\hline TOTALcognitive & EXP & 1 & 10,6 & 1,29 &, 30 \\
\cline { 2 - 6 } & CTRL & 1 & 10,0 & 1,43 &, 37 \\
\hline TOTALabilities & EXP & 1 & 13,0 & 1,30 &, 30 \\
\cline { 2 - 6 } & CTRL & 1 & 7,0 & 1,16 &, 30 \\
\hline TOTALattitudes & EXP & 1 & $\underline{\mathbf{1 3 , 0}}$ & 1,68 &, 39 \\
\cline { 2 - 6 } & CTRL & 1 & $\underline{\mathbf{4 , 6}}$ & 2,52 &, 65 \\
& & & & &
\end{tabular}

Table 1. T test applied for the general knowledge activity

We will present the results for the $2^{\text {nd }}$ outdoor activity, as it follows:

Group Statistics

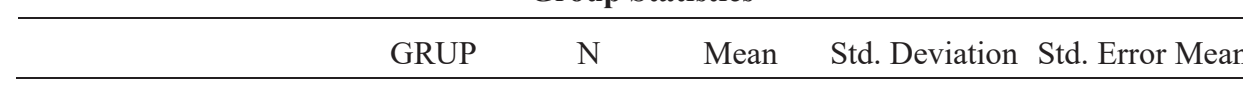




\begin{tabular}{llllll} 
TOTALcognitive & EXP & 1 & 10,8 & 2,39 &, 56 \\
\cline { 2 - 6 } & CTRL & 1 & 4,8 & 1,20 &, 31 \\
\hline TOTALabilities & EXP & 1 & 8,0 & 3,43 &, 80 \\
\cline { 2 - 6 } & CTRL & 1 & 3,3 & 2,46 &, 63 \\
\hline TOTALattitudes & EXP & 1 & $\underline{\mathbf{8 , 8}}$ & 1,84 &, 43 \\
\cline { 2 - 6 } & CTRL & 1 & $\underline{\mathbf{4 , 3}}$ & 2,02 &, 52
\end{tabular}

Table 2. T test applied for the orienteering activity

We will present the results for the $3^{\text {rd }}$ outdoor activity, as it follows:

Group Statistics

\begin{tabular}{lllrrr}
\hline & GRUP & N & & Mean & Std. Deviation \\
\hline TOTALcognitive & EXP & 1 & 10,2 &, 89 &, 21 \\
\cline { 2 - 6 } & CTRL & 1 & 8,4 &, 91 &, 23 \\
\hline TOTALabilities & EXP & 1 & 9,0 &, 97 &, 22 \\
\cline { 2 - 6 } & CTRL & 1 & 3,6 &, 72 &, 18 \\
\hline TOTALattitudes & EXP & 1 & $\underline{\mathbf{4 , 7}}$ &, 42 &, 10 \\
\cline { 2 - 6 } & CTRL & 1 & $\underline{\mathbf{1 , 4}}$ &, 50 &, 13 \\
\hline
\end{tabular}

Table 3. T test applied for the math's activity

As it can be seen in the tables presented above, (Table 1, 2 and 3), there were significant differences between the results obtained (in the third item, which measures the development of socio-emotional attitudes and attitudes towards learning) between control group and experimental group. Thus, we obtained the coefficient $\mathrm{t}=11,325$ significantly at $\mathrm{p}$ $<0,01$, between the results obtained by the experimental group $(\mathrm{m}=13, \mathrm{SD}=1,680)$ and the results obtained by the control group $(\mathrm{m}=4,67, \mathrm{SD}=2,526)$ dimension attitudes / socioemotional behaviors. This can be interpreted by the fact that at the level of the attitudes criterion, the students who participated in the training program consisting of activities related to outdoor education, show positive changes in the development of positive attitudes towards learning. This means that by taking part in outdoor education activities, the competences selected within the socio-educational attitude criterion can be significantly developed vis-à-vis those involved in the classroom instructional process. This may be due, in particular, to the freedom of expression and exploration, but also to the possibilities of communication and inter-relationship between members of the second class of study participants.

\section{Conclusions}

Firstly, significant changes can be observed in the development of the buildout of positive attitudes towards learning at second graders, by comparing experimental and control group scores. This is explained by the fact that outdoor education through related activities develops skills and changes behaviors, socio-educational attitudes to a significant level. It greatly enhances the level of autonomy and increases the level of self-confidence, increases interest and especially engagement in activities. It can be noticed that during outdoor activities, pupils were not only interested in going through the proposed activities, but they wanted to repeat the activity as many times as possible.

Secondly, through the implementation of the three integrated activities related to outdoor education, there were positive effects regarding students' attitudes regarding learning and inter-group communication, sharing ideas and information, as well as regarding pupils' 
autonomy. These results were not reflected only during the program activities, but the positive results were reflected in the classroom shortly after the completion of the outdoor education activities that were implemented at this level.

We have received a positive feedback, meaning that outdoor activities were requested by parents throughout the school year, even though there was skepticism initially about the way in which this is done and the results that can be achieved in this sense.

As well as development spaces, those around the institution were chosen, with a large courtyard and natural garden, as well as immediately adjacent spaces where outdoor activities can be successfully carried out. Thus, community members and students' parents were also involved in the experimental class. They have developed so that positive communication and student quality of life has increased considerably.

\section{References}

Bilton, H., (2010), Outdoor Learning in the Early Years: Management and innovation, (3rd. ed.), Routledge

Ilica, A., (2013), Discurs pedagogic contemporan, Învățătorul modern, Editura Chișinău, Moldova

Ionescu, M., (2003), Instrucție și educaţie. Paradigme, strategii, orientări, modele, Ed. Presa Universitară Clujeană, Cluj-Napoca

Ketchie, C., (n. d.) Benefits to outdoor education, Indigezine

Lewis, C. A., (1975), The administration of outdoor education programs, Dubuque, IA: Kendall-Hunt

Neill, J. T., (2004), Whose journeys? The outdoors and adventure as social and cultural phenomena: Critical explorations of relations between individuals, 'others' and the environment, (Humberstone, Brown, \& Richards, 2003)

Roman, A., Balaș, E., (2010), Strategii de instruire și evaluare, Editura Universității "Aurel Vlaicu", Arad

Smith, J. W., (1955), Adventure in Outdoor Education, Journal of Health, Physical Education, Recreation, Taylor \& Francis

Șerban, G., (2014), Un tip de educație nonformală: outdoor education, Resurse teoretice pentru predare-învățare în activitățile outdoor, Învățământul primar și preșcolar, 1-2/2014, 21-26 